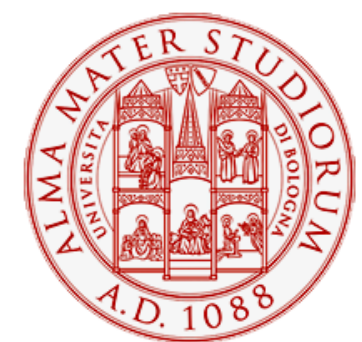

Alma Mater Studiorum - Università di Bologna DEPARTMENT OF ECONOMICS

The Change of Job Opportunities: the Role of Computerization and Institutions

\author{
Viki Nellas \\ Elisabetta Olivieri
}

Quaderni - Working Paper DSE N $N^{\circ} 804$

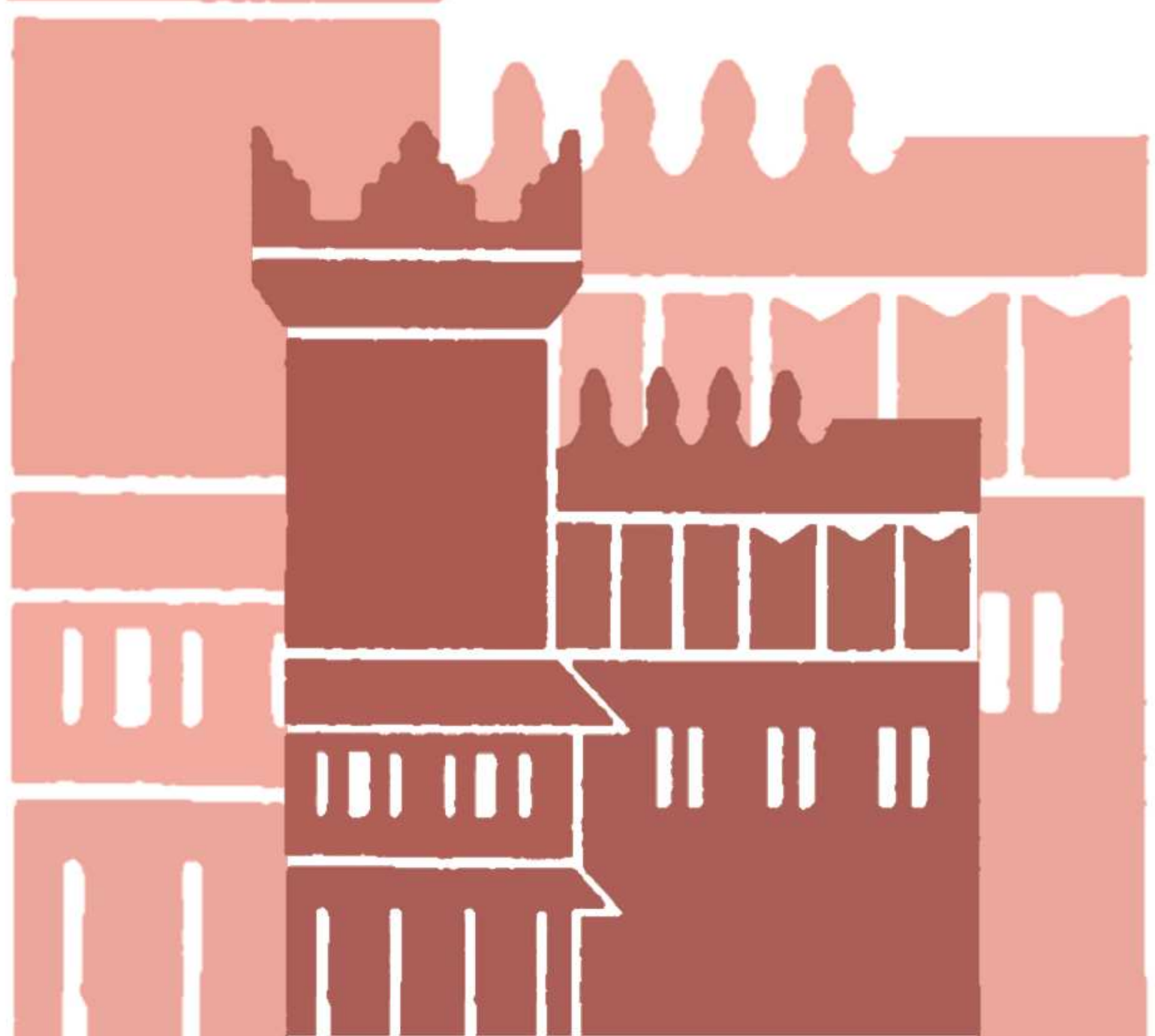




\title{
The Change of Job Opportunities: the Role of Computerization and Institutions *
}

\author{
Viki Nellas ${ }^{\dagger} \quad$ Elisabetta Olivieri ${ }^{\ddagger}$
}

\begin{abstract}
This paper studies the pattern of job opportunities over the last two decades in European countries. We find that the share of highskilled jobs have been expanding over time, while the share of mediumskilled jobs have been declining. These changes are in line with the US patterns and, according to the previous literature, they come from recent technological changes. However, our data show an interesting difference between the US and Europe: differently from the US, in Europe there is not any increase in the share of low-skilled employment. Moreover, we find that the difference between the proportions of employment hired in low-skilled and medium-skilled jobs is negatively correlated with both the unemployment rate and the degree of employment protection in the labour market.

We propose a theoretical model to study the effects of a technological shock on the employment structure in a unionized economy. By accounting for the collective bargaining process, our model may fit Continental Europe better than the ones found in the literature. We conclude that the definition of the union policy is crucial in order to explain observed cross-country heterogeneity in low-skilled employment.
\end{abstract}

Keywords: Technological change, Institutions, Employment, Europe

JEL Classification: J2, J51, O3

\footnotetext{
${ }^{*}$ We are particularly grateful to Andrea Ichino for numerous suggestions. We thank Antonio Accetturo, Francesca Barigozzi, Chiara Bentivogli, Maria Bigoni, Piero Casadio, Lorenzo Corsini, Guido Friebel, Sarah Grace See, Sauro Mocetti, Tommaso Nannicini, Paolo Onofri, Arsen Palestrini, Giulio Zanella and seminar participants at the EALE conference, the University of Bologna, the University of Toulouse 1, Prometeia and the Bank of Italy territorial meeting for useful comments. Thank to David Autor for providing data on the US. The views expressed herein are our own and do not necessarily reflect those of Institutions with which we are affiliated.

${ }^{\dagger}$ Department of Economics - University of Bologna.

${ }^{\ddagger}$ Banca d'Italia.
} 


\section{Introduction}

During the last decades, job opportunities in the US have been experiencing some crucial radical changes. As a result, there has been a fall in the proportion of middle-income jobs, which represented the core of employment during post-war years, with a concentration into high- and low-skilled occupations. ${ }^{1}$ We generally call this phenomenon job polarization.

As far as Europe is concerned, the pattern is more controversial. Goos et al. (2009), focusing on a limited range of high-, middle- and low-paid jobs, found the same employment pattern as US. Conversely, a recent paper by Oesch and Rodriguez Menes (2010) revealed a massive occupational upgrading from low-skilled jobs toward very high-skilled ones among four European countries.

We use data by Eurostat from 1993 to 2009. With respect to Goos et al. (2009) we extend the number of considered professions to all employment structure; with respect to Oesch and Rodriguez Menes (2010) we extend the analysis to all European countries. We find that almost everywhere in Europe, there has been a fall in the share of hours worked in middle-paid jobs and an increase in the share of highest-paid jobs in the last 15 years. Hence, these changes, which closely remind us of the US ones, can be considered as a global answer to some shocks which have hit labour markets of developed economies. As far as lowest paid jobs are concerned, results are quite heterogeneous among European countries. The employment share of low-paid workers has not, on average, significantly changed over time.

We propose a theoretical model which explains both (i) the upgrading in the upper half of the employment structure, which we can find in almost all developed countries -including the US; (ii) and cross-country differences in the pattern of low-paid jobs. In this model we combine:

- the presence of a technological shock. Indeed, according to the economic literature, technological change seems to be the most convincing driving force of changes in job opportunities: ${ }^{2}$ the advent of workplace computerization creates an economic incentive for employers to substitute workers hired in routine tasks with computers. Routine tasks (such as bookkeeping, clerical work, and repetitive production tasks ${ }^{3}$ ) are repetitive by nature and sufficiently well-defined that they can be carried out successfully by either workers or, alternatively, by a computer executing a program. Conversely, computerization increases

\footnotetext{
${ }^{1}$ Wright and Dwyer, 2003; Autor, 2010; Autor et al., 2006; Lemieux, 2007.

${ }^{2}$ Determining the causes of changes in the employment structure is not easy. Autor (2010) and Olivieri (2012) provide empirical evidence of the fact that in the US and in Italy the change of job opportunities has been driven by a demand-side shock (changes in wages and employment rate for homogeneous demographic groups are positively correlated). Goos et al. (2009) prove that the technological explanation is the more relevant one.

${ }^{3}$ See Autor et al. (2003) for a precise definition of these tasks.
} 
labor demand in intellectual and manual tasks (the most and the least paid ones, respectively) which cannot be performed by machines. This mechanism represents a nuanced version of skill-biased technological change proposed by Autor et al. (2006).

- the role of labor market institutions. The technological change, whatever its relevance, is always embedded in a given institutional environment and in an institutional history (Levy and Temin, 2007). This acquires even more relevance in continental Europe, where the wage structure is more rigid than in the US because of the strength of labor market institutions, which are potentially able to mitigate the effects of market forces (Krugman, 1994; OECD, 1994; Blau and Kahn, 1996).

Namely, our theoretical model analyzes the impact of computerization on employment in different parts of the skills distribution accounting for the presence of unions.

We imagine an economy with three types of human labor inputs in production: high-skilled workers performing non-routine cognitive tasks, moderately-skilled workers performing routine tasks, and low-skilled workers hired in non-routine manual tasks. Our point of reference is the framework of Autor et al. (2006), where computerization is embodied by an exogenous shock, i.e., the decline in the real price of computers. The main difference between our model and theirs is the labor market environment; while they analyze the effects of computerization in a competitive framework (consistent with the US case), we introduce some rigidities related to the presence of union. In our model, the union sets the highest possible wage compatible with a certain employment target and then the firm chooses its labor demand (Blanchard and Bummers, 1986). The size of the union's employment target is crucial to determine the effects of computerization on the labor market and can be interpreted as a consequence of the union bargaining power. Since only employed individuals can be unionized, the unions' strength is embodied in an employment target which exclude non-employed individuals.

The model shows that the technological change induces (i) a reduction of the employment share of routine labor tasks, typically replaced by computer capital; (ii) an increase in the employment share of abstract labor tasks, that are complements to computers, due to the workers' choice to move from medium to high-skilled jobs; (iii) a shift in labour supply from medium to low-skilled jobs whose effects on low-skilled manual employment strictly depend on the union employment target. When unions protect only their members (currently employed individuals), the effects of the increase in low-skilled supply will be weak. Thus, according to our theoretical analysis, unions can minimize the effects of the technological shock on the employment structure, and at the same time, may create involuntary unemployment.

All these theoretical predictions are well supported by the empirical ev- 
idence. In particular, we show that the difference in the employment shares of low-skilled and medium-skilled jobs is negatively correlated both with the national employment rate and the degree of employment protection. This evidence suggests that the lack of employment growth among low-skilled jobs may hide a creation of less new job opportunities.

Our paper contributes both to the literature that studies the change in job opportunities and to the literature on the effects of institutions on the labour market. To our knowledge, this is the first paper on changes in job opportunities that integrates technological and institutional elements in a theoretical framework. Indeed, one of the novelties of our paper is that we jointly consider these two aspects and we derive the effects of computerization on the employment structure depending of the attitude of labour market institutions.

The paper is organized as follows: in section 2 we show the employment pattern of some European countries. In section 3 we describe our theoretical model and in section 4 we test the main predictions of the model. Finally, we conclude in section 5 .

\section{Change in Job Opportunities in Europe}

While there is a large consensus over the fact that there has been a clear job polarization pattern in the US in the last two decades, as far as Europe is concerned, things are more controversial. Some authors reveal that the polarization trend has been crucial also in Europe: Goos et al. (2009) show that the share of worked hours in medium-paid jobs declined by over 7 percentage points from 1993 to 2006, while the share in high-paid and low-paid jobs increased by 6.2 and 1.6 percentage points, respectively. Conversely, a recent work by Oesch and Rodriguez Menes (2010) revealed a massive occupational upgrading in some European countries (Britain, Germany, Spain, and Switzerland): employment has expanded most at the top of the occupational skill ranking (among managers and professionals) and has decreased both in mid-range (clerks and productions workers) and lowrange occupations (personal service workers).

We try to solve this puzzle using data collected by Eurostat which come from national labour force surveys. This dataset is homogeneous in terms of sample strategies and uses some harmonized definitions for the major aggregates of the labor force. Even the classification of occupations is uniform across countries and over time. This choice, differently from Oesch and Rodriguez Menes (2010), makes our results strictly comparable across countries and over time. We restrict our analysis to employed workers, regardless of whether they are filled by wage-earners, self-employed workers or employers. We define occupations on the basis of the International Standard 
Classification of Occupations (ISCO), excluding those workers employed by the military and agricultural occupations because of data quality.

Tables 1 and 2 show which are the occupations which have experienced the sharpest decline and increase in the employment shares. In most countries the deeper decrease has concerned medium-paid jobs: clerks, service workers and crafts. In Denmark, Portugal, and Norway the proportion of managers of small enterprises has deeply decreased, while in Croatia the sharpest fall has concerned low-skilled workers hired in mining, construction, manufacturing, and transport. Furthermore, the employment shares of high-skilled workers (managers and associate professionals) in all countries display the highest rates of growth. All countries but Italy saw the deeper decrease in medium-paid jobs: clerks and crafts. In Italy the proportion of low-skilled workers hired in the trade sector has sharply decreased. Furthermore, in every country but the United Kingdom, Romania, and Portugal, the employment shares of high-skilled workers (managers and associate professionals) have displayed the highest rates of growth.

\begin{tabular}{ccrr}
\hline Country & Occupation & Skill req. & Ch. in Empl. Sh. \\
\hline AT & Metal, machinery and related trades workers & 12.6 & -3.1 \\
BE & Metal, machinery and related trades workers & 11.6 & -3.2 \\
CY & Personal and protective services workers & 13.4 & -2.9 \\
CZ & Labourers in mining, constr., manufact. and transp. & 11.7 & -2.4 \\
DE & Extraction and building trades workers & 12.7 & -1.0 \\
DK & Managers of small enterprises & 13.2 & -2.9 \\
ES & Office clerks & 14.2 & -4.2 \\
FR & Office clerks & 13.2 & -4.0 \\
GR & Other craft and related trades workers & 9.9 & -4.2 \\
HU & Metal, machinery and related trades workers & 12.7 & -2.1 \\
IT & Models, salespersons and demonstrators & 11.2 & -6.2 \\
NL & Machine operators and assemblers & 10.2 & -1.4 \\
NO & Managers of small enterprises & 14.1 & -4.0 \\
PT & Managers of small enterprises & 10.1 & -4.2 \\
RO & Metal, machinery and related trades workers & 12.8 & -4.8 \\
SK & Metal, machinery and related trades workers & 13.0 & -3.4 \\
UK & Office clerks & 13.0 & -3.7 \\
\hline
\end{tabular}

Table 1: Occupations with the largest decrease in the employment share. Source: Eurostat, 1993-2009.

Now we explore how the change in European employment has been linked to the jobs' skill content. Figure 1 shows the change in the share of working hours from 1993 to 2009 for 16 European countries by distinguishing among three skillhomogeneous groups of occupations: low-, middle- and high-skilled professions. We call low-skilled jobs all elementary occupations (group 9 in ISCO 1-digit classification). Medium-skilled jobs include plant and machine operators and assemblers; craft and related trades workers; service workers and shop and market sales workers; and clerks (groups 4-8 in ISCO 1-digit classification). Finally, high-skilled jobs include legislators, senior officials and managers; professionals; and technicians and associate professionals (groups 1-3 in ISCO 1-digit classification).

The figure shows that in all these countries but Portugal, the employment 


\begin{tabular}{ccrr}
\hline Country & Occupation & Skill req. & Ch. in Empl. Sh. \\
\hline AT & Other associate professionals & 13.3 & 6.6 \\
BE & Other professionals & 16.9 & 3.2 \\
CY & Corporate managers & 16.6 & 2.8 \\
CZ & Other associate professionals & 14.1 & 3.5 \\
DE & Other professionals & 16.7 & 1.1 \\
DK & Other associate professionals & 14.0 & 2.7 \\
ES & Other associate professionals & 15.2 & 4.2 \\
FR & Corporate managers & 15.9 & 6.8 \\
GR & Other associate professionals & 15.3 & 2.4 \\
HU & Other professionals & 17.3 & 2.0 \\
IT & Managers of small enterprises & 11.1 & 6.2 \\
NL & Other professionals & 17.0 & 3.1 \\
NO & Other professionals & 16.6 & 4.0 \\
PT & Sales and services elementary occ. & 8.7 & 3.6 \\
RO & Personal and protective services workers & 12.8 & 3.4 \\
SK & Other associate professionals & 14.5 & 3.3 \\
UK & Personal and protective services workers & 12.9 & 3.2 \\
\hline
\end{tabular}

Table 2: Occupations with the largest increase in the employment share. Source: Eurostat, 1993-2009.

share of high-skilled occupations has increased over time; conversely, the share of medium-skilled professions has decreased everywhere but Romania. As far as lowskilled professions are concerned, the pattern is heterogeneous among European countries: this share has increased only in few countries (Croatia and Portugal) similar to the US; the rest of the countries have seen a fallen. On average, the proportion of low-skilled jobs in Europe has not significantly changed.

Change in job opportunities in Europe

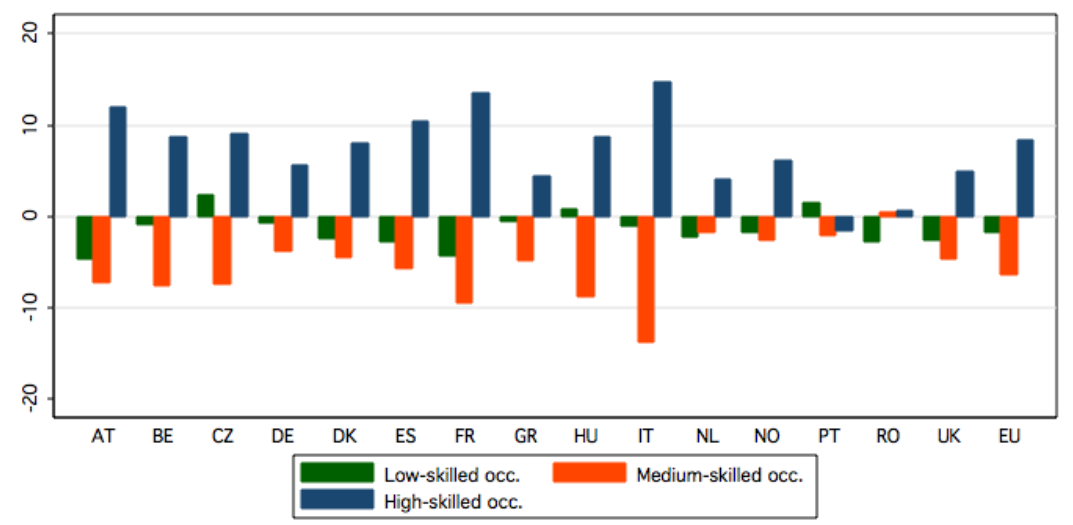

Figure 1: Changes in employment shares by skill group of professions. Source: Eurostat, 1993-2009. The data include all workers, excluding those employed by the military and in agricultural occupations. Employment shares in 1993 are imputed on the basis of average annual changes for countries with shorter data spans.

Now we focus on 6 major continental European countries: Austria, France, Germany, Greece, Italy, and Spain (Figure 2). We define occupations on the basis of the 3-digits ISCO classification; thus, we end up with 99 different occupations. 
For every occupation we compute the skill content using the educational level as a proxy of skills. ${ }^{4}$ Then, these occupations are ranked on the x-axis by their skill requirement. The $y$-axis of the figure corresponds to the change in employment (as a share of total employment) at each decile of the skill distribution of jobs from 1993 to 2009. Since the sum of shares must equal one in each decade, the change in these shares across decades must total to zero. Consequently, the figure measures the employment growth in each occupation relative to the whole.

Figure 2 confirms that the proportion of medium-skilled jobs has fallen in every country; the fall is particularly deep in Italy and France. Furthermore, all countries have experienced a growth in the average of the highest-skilled occupations. Again, this growth is particularly significant in Italy and France, where the employment shares of legislators, senior officials, managers, and professionals have increased by 7 and 9.2 percentage points, respectively. In the first decile of the skill rank we do not observe any significant change in Austria, Germany, and France; we do find a decrease in Spain and Italy and an increase in Greece.

Thus, whereas somewhere in Europe there is an employment pattern which reminds to the US labour market, the most relevant change deals only with the upper part of the employment structure. There we observe a clear upgrading from medium- to high-skilled jobs during last 15 years, consistent to what Oesch and Rodriguez Menes (2010) found for Spain, Germany, United Kingdom, and Switzerland.

In our analysis the ranking of occupations is fixed over time. We test the assumption that ranking does not change a lot over time using the Spearman's correlation between the ranking of 3 digits ISCO occupations at the beginning and at the end of the period in each country. These correlations are strong (on average 0.90), spanning from 0.83 for Austria to 0.94 for Greece. On the other side, in principle, this ranking could be different across countries; this is not a problem since the analysis aims at comparing the evolution of good and bad jobs in each country and not at tracing the evolution of the same occupations across countries. ${ }^{5}$ Regardless, the occupational skill structure is very similar in our six countries (Spearman's correlations among countries are on average equal to 0.87 and never lower than 0.82 ).

\section{The Theoretical Model}

The European pattern does not seem to be consistent with the simple computerization hypothesis studied by Autor et al. (2006) for a perfect competitive labor market, where we should observe an employment growth only in the bottom and in the upper part of the skills distribution. Indeed, even if we observe a significant reduction of employment in middle-skilled jobs, there is no evidence of employment increase among the low-skilled occupations. ${ }^{6}$ Hence, we propose a theoretical model that analyzes the impact of technological diffusion on wages and employment in a more complex labor market, characterized by the presence of the union.

\footnotetext{
${ }^{4}$ We determine the skill requirement using the average number of years of schooling of workers. We derive this information from the individual highest educational degree.

${ }^{5}$ See Oesch and Rodriguez Menes, 2010.

${ }^{6}$ Also the standard SBTC does not explain the observed pattern. This phenomenon predicts a decline in the bottom tail of the skill distribution but no the large decrease of middle-skilled jobs.
} 
Employment change in job quality
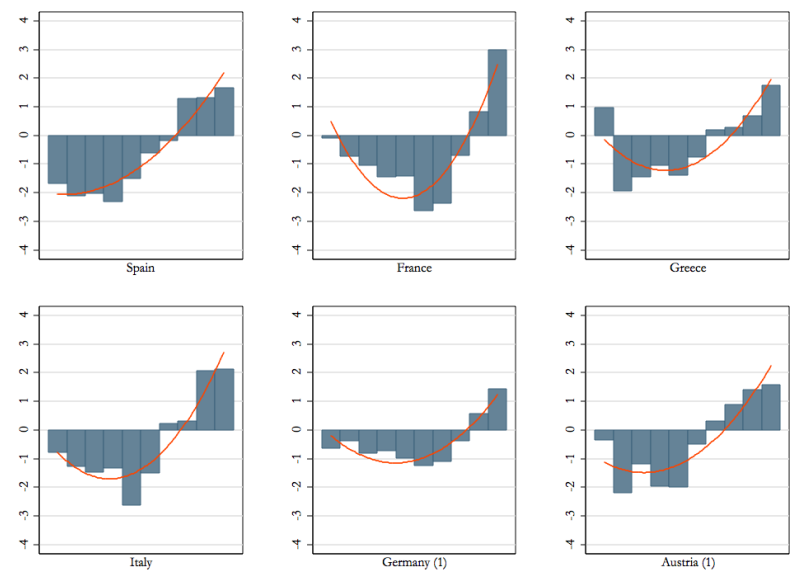

Figure 2: Changes in employment shares by decile of the skill distribution of jobs. Source: Eurostat, 1993-2009. The data include all workers, excluding those employed in military and agricultural occupations.

Following the simple framework of Autor et al. (2006), technological spread is embodied by an exogenous decline in the real price of computers and similar technologies. Indeed, the decrease of computing power price has been the main responsible factor of computer diffusion in productive processes.

We study an economy with three different groups of workplace tasks: abstract (A), routine (R), and manual (M). These groups roughly correspond to high-, intermediate- and low-skilled jobs. The technological shock hits the workers hired in these three activities in different ways (Levy and Murname, 2004). In particular, we assume that: (i) computer capital is a close substitute for human labor in routine cognitive and manual activities; ${ }^{7}$ (ii) routine tasks are complements of abstract tasks (e.g., coordination activities and problem solving) and, to some extent, also of manual activities.

Aggregate output is produced using the Cobb-Douglas production function:

$$
Y=L_{A}^{\alpha}\left(L_{R}+K\right)^{\beta} L_{M}^{\gamma}
$$

where $\alpha, \beta, \gamma \in(0,1)$ and $\alpha+\beta+\gamma=1$. Only workers can perform abstract and manual tasks $\left(L_{A}, L_{M}\right)$, while routine tasks can be done either by workers $\left(L_{R}\right)$ or by computer capital $(K) . K$ is measured in efficiency units and is elastically supplied to routine tasks at price $\rho$ per efficiency unit.

The first novelty of this framework is the introduction of some rigidities related to the union activity and the possibility to analyze the effects of the technological shock in alternative institutional settings.

\footnotetext{
${ }^{7}$ The substitutability assumption is reasonable given that routine tasks (such as bookkeeping, clerical work and repetitive production tasks) are repetitive and sufficiently well defined that they can be performed almost equally well by computer executing a program or, alternatively, by workers. Moreover, Autor et al. (2003) deeply analyze this issue and provide empirical support to this theoretical assumption.
} 
We assume that the abstract and routine labor markets are perfectly competitive, while in the manual labor market, employment and wages depend on the interaction between the union and the firm. Consistent with the Blanchard and Summers's (1986) framework, the union's goal is to reach the highest possible wage compatible with a certain employment target in the manual labor market. ${ }^{8}$ This target $\left(L_{M}^{*}\right)$ is a function of the number of union members, $L_{M}^{I}$, (employed workers at the moment of the bargaining process) and of the total labor supply for this task, $S_{M}$.

The union employment target is:

$$
L_{M}^{*}=\phi L_{M}^{I}+(1-\phi) S_{M}
$$

where $\phi \in(0,1)$ represents the weight assigned to current employed people during the bargaining process. The higher is the value of $\phi$, the less the union takes into account the effects of the bargaining process on the employment opportunities of all workers supplying labor $\left(S_{M}\right)$. In the limit case in which $\phi$ is equal to one, then $L_{M}^{*}=L_{M}^{I}$; when $\phi=0$ we go back to the perfect competitive case of Autor et al. (2006). Therefore, we can consider $\phi$ as a measure of how much market-oriented the union is and also as a measure of the union's strength. Indeed, only currently employed workers can be unionized; thus, the higher is the union political power, the more that the union can protect its members. When $\phi$ is equal to one, the union has the leading role in the bargaining process and can impose its pure strategy which fully protects its members. When $\phi=0$ the market acts in a competitive way.

The wage definitions for abstract, routine, and manual workers are different, depending on the functioning of the corresponding market. While abstract and routine workers are paid at their marginal productivity, the manual wage depends on the interaction between the union and the representative firm. Once the bargaining process has led to the optimal wage, the level of the manual employment $L_{M}$ is chosen by the firm according to its labor demand function:

$$
L_{M}=\left(\frac{\gamma L_{A}^{\alpha}\left(L_{R}+K\right)^{\beta}}{w_{M}}\right)^{\frac{1}{1-\gamma}} .
$$

When no shock hits the economy, $L_{M}^{*}=E\left(L_{M}\right)=L_{M}$, and we obtain $w_{M}$ from equations (2) and (3):

$$
w_{M}=\gamma L_{A}^{\alpha}\left(L_{R}+K\right)^{\beta}\left[\phi L_{M}^{I}+(1-\phi) S_{M}\right]^{\gamma-1} .
$$

In this economy, there are many income-maximizing workers. Each of them is endowed with a vector of three skills, one for each production task $\left(E_{i}=\right.$

\footnotetext{
${ }^{8}$ It is reasonable to treat separately the three labor markets since the bargaining process sets labor conditions for every industrial sector and worker qualification. The assumption according to which the routine labor market is competitive is not binding. Our results stay valid even if the wage setting process in the routine market is equal to the one in the manual market. Indeed, the substitutability between routine workers and computers forces unions to set a routine wage equal to the marginal productivity of the routine input; otherwise no worker would be employed in routine tasks and the union employment target -whatever it is- would not be satisfied.
} 
$\left.\left(a_{i}, r_{i}, m_{i}\right)\right)$. College-graduate workers are endowed with $\lambda$ efficiency unit of abstract skill that is supplied to abstract tasks and with $\eta$ efficiency units of routine skill. $\eta$ and $\lambda$ are continuous variables distributed on the unit interval $(\lambda \in(0,1)$, $\eta \in(0,1))$ with positive probability mass at all points. College workers have the endowment vector $E_{i}=(\lambda, \eta, 0)$ and can choose to supply their efficiency units to either abstract or routine tasks.

Every non-graduate worker has one efficiency unit to supply to manual tasks and cannot perform abstract tasks. Moreover, they are characterized by $\eta$ efficiency units of routine skill. Therefore, their endowment vector is $E_{i}=(0, \eta, 1)$ and they can choose to supply their efficiency units to either manual or routine tasks.

Individual supply choices of workers are determined by a self-selection rule. According to it, workers select themselves into one specific task given their ability, the wage levels and, in the case of non-graduate workers, taking also into account the probability of being hired in each task.

Consider the non-graduate workers. Let $w_{R}$ and $w_{M}$ be the wage paid to routine and manual tasks per efficiency unit; then, each worker will compare $w_{M}$ and $\eta w_{R}$. The higher the value of $\eta$ is, the more likely it is that the worker chooses a routine job. Furthermore, supply choices depend on the probability of having a job in the two sectors. Since the routine market equilibrium is equal to the competitive outcome, at the equilibrium, no worker will be involuntarily unemployed. In the manual market, the probability of being employed depends on $\phi$. When $\phi=0$ there is no unemployment. Conversely, a more restrictive employment target $(\phi>0) \mathrm{im}-$ plies a lower probability of finding a job in the manual sector and therefore, a lower manual labor supply. Summing up, the labour supply in the manual labour market is:

$$
S_{M}=\frac{w_{M}}{\eta w_{R}}(1-\phi)
$$

where:

- $\frac{\partial S_{M}}{\partial \frac{w_{M}}{\eta w_{R}}}=\alpha(1-\phi)$ is equal to or greater than zero. This means that the higher the relative wage, the higher is the labor supply in the manual sector.

- $\frac{\partial^{2} S_{M}}{\partial \frac{w_{M}}{\eta w_{R}} \partial \phi}=-\phi$ is equal to or lower than zero. This derivative implies that workers are more sensitive to changes in relative wages when $\phi$ is low.

Also routine labor supply is a function of the relative wage and the union behavior. In particular, both $\frac{\partial S_{R}}{\partial \phi}$ and $\frac{\partial^{2} S_{R}}{\partial \frac{w_{M}}{\eta w_{R}} \partial \phi}$ are equal to or greater than zero. Thus, an increase in relative wages induces a deeper reduction in $S_{R}$ when $\phi$ is low.

Consider the choices of college-graduate workers. Let $w_{A}$ and $w_{R}$ be the wage paid to abstract and routine tasks per efficiency unit. Now the comparison is between $\lambda w_{A}$ and $\eta w_{R}$. The lower is the value of the ratio $\eta / \lambda$ and the higher is the relative wage $w_{A} / w_{R}$, the more likely it is that the worker chooses an abstract job.

\subsection{The Effects of the Technological Shock on Employment}

Now we consider the effects of a positive shock on the labor market, paying special attention to the manual sector. In particular, the exogenous force that hits 
the economy is the reduction of the computer price, $\rho$.

Let us first consider what is the effect on the routine sector. Since computer capital is a perfect substitute for routine labor input, $w_{R}=\rho$, and, consequently, a decline in $\rho$ reduces $w_{R}$ on a one-to-one basis. With downward-sloping factor demand curves $\left(R^{\prime}(\rho)<0\right)$, the decline in $\rho$ raises the demand for routine tasks. This increase in the demand for routine tasks leads to an increase in the abstract and manual labor demands because of the existing complementarities. Both computer capital and routine labor inputs are potentially able to satisfy this additional routine demand, but it will be satisfied by computer capital. Moreover, computers will also substitute some routine workers. In fact, when $\rho$ declines, the ratio between manual and routine wages increases and some workers will decide to switch from routine to manual tasks (Autor et al., 2006). These workers are those who have the lowest values of $\eta$. Also the ratio $w_{A} / w_{R}$ increases and this induces some college-graduate workers (those having a low value of $\eta / \lambda$ ) to shift from the routine to the abstract sector. Since the shock reduces $S_{R}$, the employment in routine tasks declines.

The non-graduate worker's decision to supply labor is also related to the ease of finding a job in each sector; thus, the magnitude of the labor supply change will depend on the value of the parameter $\phi$. Noteworthy, the stricter is the union employment policy (the higher $\phi$ ), the lower is the reduction in $S_{R}$. In the limit case, when $\phi=1$, nobody will move from the routine to the manual sector and no increase in the manual labor supply will take place. This implies that the implementation of new technologies might be lower when unions tend to protect only their members.

In the manual sector there is an increase both in labour demand -because of factor complementarieties- and in labour supply. In spite of that, the change depends on the union's policy and on the predictability of the technological shock. If the union does not expect the increase in the manual demand, then $L_{M}^{*}=E\left(L_{M}\right)<$ $L_{M}$, and whatever the value of $\phi$, the manual employment increases. Actually, it is reasonable to assume that the union can anticipate technological shocks. ${ }^{9}$ Then, the resulting wage embodies the shock, and the employment level coincides with the union expectation. In this case, also the effects on the manual labor market crucially depend on $\phi$ : only when $\phi<1$ the union considers the change of $S_{M}$ during the bargaining process, and so an higher $S_{M}$ leads to a positive effect on manual employment. Conversely, if $\phi=1$, an increase in the manual supply does not affect the union employment target and, consequentely, workers do not have incentive to move form the routine to the manual sector even if the relative wage increases. Indeed, $-\frac{\partial L_{M}^{*}}{\partial \rho}=-(1-\phi) \frac{\partial S_{M}}{\partial \rho}$ is equal to zero if $\phi=1$ and greater than zero otherwise.

The second cross partial derivative is:

$$
-\frac{\partial L_{M}^{*}}{\partial \rho \partial \phi}=-\left[(1-\phi) \frac{\partial S_{M}}{\partial \rho \partial \phi}-\frac{\partial S_{M}}{\partial \rho}\right]<=0 .
$$

Therefore, the higher $\phi$ is, the lower the effect of the computer price decline on

\footnotetext{
${ }^{9}$ This assumption is reasonable for all those economies a bit far from the technological frontier (as many European countries). Indeed, these economies generally face a given shock some years later than the US, so they expect the technological innovations and their consequences on the labor market.
} 
manual employment, to the limit that when $\phi=1$ there is no employment change. ${ }^{10}$

Finally, the technological shock increases the labour demand in the abstract labour market, because of factor complementarities. At the same time, the increase of $w_{A} / w_{R}$ induces some college-gradaute workers to switch from the routine to the abstract sector, generating also a positive supply shock. Therefore the abstract employment share increases. ${ }^{11}$

Proposition 1 A decline in the price of computers leads to a shift of labour supply from routine (medium-skilled) tasks to manual (low-skilled) tasks and from routine (medium-skilled) tasks to abstract (high-skilled) tasks. As a result, there is a decrease in the employment share of medium-skilled jobs and an increase in the share of low-skilled and high-skilled jobs. The magnitude of the changes in the routine and manual employment is a function of the union's bargaining strategy: the more it protects only its members (currently employed workers) in the manual labour market ( $\phi$ close to 1), the weaker is the difference in the employment shares of lowand medium-skilled jobs.

\subsection{The Effects of the Technological Shock on Wages}

In order to analyze the effects of a decline in computer price on wages, we differentiate the three wage equations with respect to $-\rho$. As far as the routine wage is concerned, our result is obvious and strictly related to the substitutability between computers and routine workers:

$$
-\frac{\partial w_{R}}{\partial \rho}=-1
$$

Formally, the impact of the technological diffusion on $w_{M}$ is:

$$
\begin{aligned}
-\frac{\partial w_{M}}{\partial \rho}= & \gamma(1-\gamma)(1-\phi) L_{A}^{\alpha} R^{\beta}\left[\phi L_{M}^{I}+(1-\phi) S_{M}\right]^{\gamma-2} \frac{\partial S_{M}}{\partial \rho}+ \\
& -\beta \gamma L_{A}^{\alpha} R^{\beta-1} \frac{\partial R}{\partial \rho}\left[\phi L_{M}^{I}+(1-\phi) S_{M}\right]^{\gamma-1} .
\end{aligned}
$$

The effect of the technological spread on $w_{M}$ is not clear: two opposite effects act simultaneously. On one hand, complementarities would induce an increase in the manual demand with a positive pressure on manual wage. On the other hand, workers' shift from the routine labour market induces an increase in $S_{M}$ that tends

\footnotetext{
${ }^{10}$ The insider-outsider framework developed in the model has been choosen because it represents well the union behaviour in the continental European countries. Moreover, it allows to develop a simple and clear analysis. As robusteness check, we solved the bargaining process using also a standard right to manage model (Nickell et al., 1983) and the results we got are in line with those presented in the Section 3.1. Indeed, the technological shock has a positive effect on the low-skilled employment; but this employment increase is lower the higher is the bargaining power of the union. Results are available upon request.

${ }^{11}$ The share of abstract employment on total employment should increase, as long as $0<\phi<1$, also because the technological change reduces the total employment in the economy (see section 3.3)
} 
to decrease the manual wage. The final outcome depends on the prevailing force. Note that $\frac{\partial^{2} S_{M}}{\partial \frac{w_{M}}{\eta w_{R}} \partial \phi}$ is negative or equal to zero. Thus, the higher is the value of $\phi$, the lower is the weight of the supply-side effect. ${ }^{12}$

Finally, an uncertain wage effect emerges also in the abstract labor market

$$
-\frac{\partial w_{A}}{\partial \rho}=-\alpha L_{A}^{\alpha-1}\left[\beta R^{\beta-1} \frac{\partial R}{\partial \rho} L_{M}^{\gamma}+\gamma R^{\beta} L_{M}^{\gamma-1} \frac{\partial L_{M}}{\partial \rho}\right]+\alpha(\alpha-1) L_{A}^{\alpha-2} \frac{\partial L_{A}}{\partial \rho}\left[R^{\beta} L_{M}^{\gamma}\right] .
$$

This is due to the increase in the demand for abstract tasks (induced by the complementarities between routine and abstract tasks), which is followed by a countervailing growth in labor supply, due to the workers' self selection. The direction of the wage change depends on the prevailing force.

Proposition 2 A decline in the price of computers may lead to a stronger increase in wage at the extremes of the wage distribution than at the middle.

\subsection{The Effect of The Shock on Unemployment}

In this setting, technological change may create involuntary unemployment. Indeed, when the cost of the routine input declines, some workers will stop supplying labour in routine tasks and start supplying labour in manual ones, even if union's employment target does not guarantee them a manual job.

In other words, despite the fact that after the technological shock both manual labour demand and supply increase, the union can set an employment target which can impede an increase in the manual labour supply.

Formally, let $U_{M}=S_{M}-L_{M}^{*}$ be the number of unemployed individuals. When $\rho$ declines, we have:

$$
-\frac{\partial U_{M}}{\partial \rho}=-\left[\frac{\partial S_{M}}{\partial \rho}-(1-\phi) \frac{\partial S_{M}}{\partial \rho}\right]=-\left[\frac{\partial S_{M}}{\partial \rho} \phi\right]>=0
$$

Equation (10) shows that unemployment increases after the technological shock. Noteworthy, in the limit case $\phi=1$ the derivative $-\frac{\partial U_{M}}{\partial \rho}$ is equal to zero. In this particular situation there is no change in the labor supply, and unemployment does not emerge. When $\phi>0$, the union transfers the most part of the positive demand shock to the wage of its members, instead of allowing an employment increase. The union, by bargaining for a high level of low-skilled wage, decreases inequality in the lower tail of the earning distribution, at the cost of an increasing number of unemployed workers. Thus, the unemployment creation varies with the union policy. In particular:

$$
-\frac{\partial U_{M}}{\partial \rho \partial \phi}=-\left[\frac{\partial S_{M}}{\partial \rho \partial \phi} \phi+\frac{\partial S_{M}}{\partial \rho}\right]>=0
$$

\footnotetext{
${ }^{12}$ In the limit case in which $\phi=1$ the supply-side effect does not matter and all the positive demand shock (due to the technological change) is transfered by the union to the wage, through the bargaining process. Indeed, $-\frac{\partial w_{M}}{\partial \rho}=-\beta \gamma L_{A}^{\alpha} R^{\beta-1} \frac{\partial R}{\partial \rho} L_{M}^{\gamma-1}>0$
} 
Therefore, the higher $\phi$, the less the supply increase in the manual sector is absorbed because the bargained wage is such that the firms are not willing to hire all the new wotkers shifted from the routine to the manual sector.

Proposition 3 There is a positive and monotonic relationship between the attitude of the union to protect its members and the unemployment level. Therefore, the lower si the difference in the employment shares of low- and medium-skilled jobs, the higher is the unemployment rate.

\section{The International Evidence}

The theoretical model provides some predictions on the effects of the technological shock on employment and wage structures, depending on country-specific institutions. In this section we are going to verify how those predictions fit real data. Unfortunately, both technological change and labor market policies are variables with a lot of measurement problems; thus, this analysis could not aim at verifying some causal relationships, but only to show whether theoretical predictions are reliable from a quantitative point of view.

\subsection{Prediction 1: Institutions and Changes in the Employ- ment Structure}

US and Europe have both been hit by the same kind of technological change during the last decades, but they are characterized by different institutional settings. Even if it is difficult to define precisely what are labor market institutions, continental Europe shows stronger labour market institutions as far as either (i) labor taxes, (ii) law and regulations covering employees' rights, and (iii) trade unions and the structure of wage bargaining are concerned. Considering labor taxes, OECD compares the shares of employee earnings taken by governments in different countries through taxation by calculating the difference between labor costs to the employer and the net take-home pay of the employee, including any cash benefits from government welfare programs. According to these data, the total tax wedge for a single individual without children with an average income in 2008 was equal to $30.1 \%$ in the US and $46.5 \%$ in Italy, $52.0 \%$ in Germany and $49.3 \%$ in France. Thus, total rates in continental Europe are significantly higher than in the US. Furthermore, laws referring to the treatment of employees by companies (which include working hours, annual leave, health and safety, employee representation rights, employment security, and compensation insurance) presents strong cross-country heterogeneity with a higher level of regulation in southern Europe. All these features are strictly related to the labor cost and may have additional effects on productivity; that is why many papers looked at the relationship between the institutional setting of the labor market and the overall economic performance, focusing mainly on unemployment and growth. ${ }^{13}$ Finally, we provide some information to clarify the role of unions across countries. The unionization rate in 2004 was about $30 \%$ in Europe and $11.5 \%$ in the US. This evidence shows that the European labor market

\footnotetext{
${ }^{13}$ See Nickell and Layard (1999) for a review.
} 
is clearly more affected by the union activity than the US one. Indeed, many European countries have their wages determined by collective agreements which are negotiated at the plant, firm, industry, or national level. In many of these countries, even if the number of union members is low, most workers have their wages set by union agreements: union pay is legally extended to cover non-union firms or workers. For this reason, more than the unionization rate, it is the collective bargaining coverage that measures the real extent to which salaried workers are subject to union-negotiated terms and conditions of employment. According to the OECD, in 2000, the coverage rate was $14 \%$ in US and, on average, more than $80 \%$ in continental Europe, ${ }^{14}$ where at least two out of three workers were covered by bargained setting. Moreover, the coverage rate had been stable or increasing during the previous twenty years. Data based on survey data about wages reveal that the same difference was still present in 2006 (Tijdens and Van Klaveren, 2007). Also, the collective agreement coverage rate about employment protection legislation differs a lot across countries. According to OECD, in 2009, it was roughly $80 \%$ in continental Europe, $35 \%$ in UK, and $13 \%$ in US.

According to our model, the decrease in the employment share of mediumskilled jobs and the increase in low-skilled jobs are strictly related to the union's policy. Thus, we expect that the European case is consistent with our theoretical predictions when there is a high value of $\phi$, while the US case when there is lower level of $\phi$. This prediction is roughly consistent with the evidence in Section 2, where we showed that in continental European countries there is not the same growth in low-skilled employment experienced in the US (Autor et al., 2006).

Now we show that even differences in employment changes across European countries can be explained by differences in the strength of labour market institutions. In particular, we exploit the correlation between these two variables using data from 1993 to 2009 from 15 European countries. ${ }^{15}$

We use the employment protection legislation (EPL) index elaborated by OECD as a proxy of the strictness of the union policy. Indeed, most part of the employment protection derives from the collective bargaining process. This index captures the degree of labor market rigidity (in terms of hiring and firing) and it will be low when the labour market is flexible.

According to the theoretical framework, the difference in the employment share of low-skilled ${ }^{16}$ and middle-skilled jobs ${ }^{17}$ is strictly related to the institutional environment. In particular, the higher is this difference, the less unionized is the labour market.

Figure 3 shows that EPL and the difference in the low-skilled and the middleskilled employment shares are negatively correlated (the slope of the curve is differ-

\footnotetext{
${ }^{14}$ The collective bargaining coverage rate was $80 \%$ for Italy as well as for Spain, $90 \%$ in Finland and Sweden and 30\% in UK

${ }^{15}$ Austria, Belgium, Croatia, Denmark, France, Germany, Greece, Holland, Hungary, Italy, Norway, Portugal, Romania, Spain and United Kingdom.

${ }^{16}$ Here considered as the elementary occupations (group 9 in ISCO 1-digit classification).

${ }^{17}$ Plant and machine operators and assemblers; craft and related trades workers; service workers and shop and market sales workers; clerks (groups 4-8 in ISCO 1-digit classification).
} 
EPL and the difference in the proportion of low and medium-skilled jobs

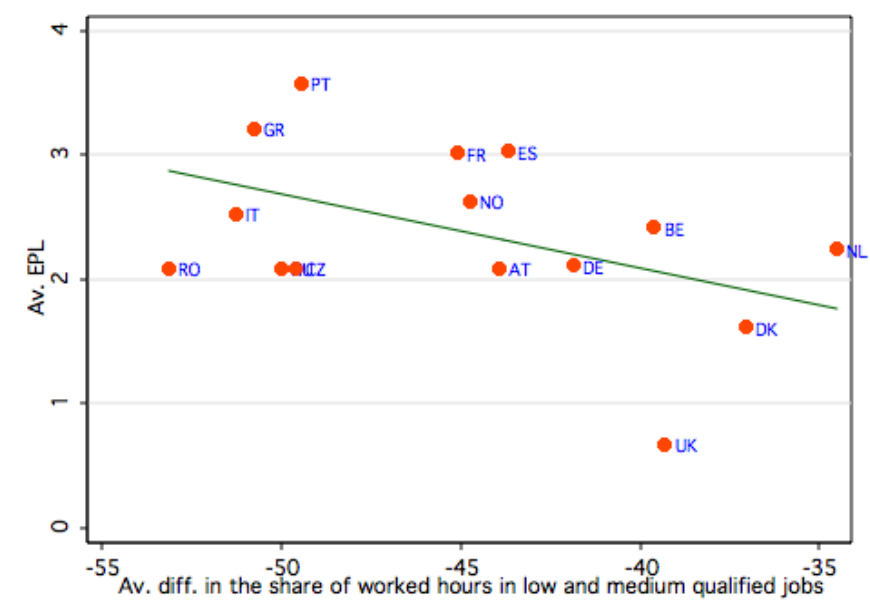

Figure 3: Source: Eurostat and OECD, 1993-2009.

ent from zero at 1\%). In a regression of EPL on this difference, which controls for country fixed effects (table 1), we observe a statistically significant coefficient. Thus, the proportion of low-skilled employment is higher with respect to the proportion of medium-skilled employment when labor market institutions have a market-oriented strategy, as predicted by our model.

EPL and the difference in the proportion of low- and medium-skilled jobs

\begin{tabular}{cc}
\hline EPL & $-5.19^{* * *}$ \\
& $(0.59)$ \\
Country FE & YES \\
$R^{2}$ & 0.77 \\
Obs. & 177 \\
\hline
\end{tabular}

Table 3: Source: Eurostat and OECD, 1993-2009. The regression includes data on Austria, Belgium, Croatia, Germany, Denmark, Spain, France, Greece, Hungary, Italy, Holland, Norway, Portugal, Romania and United Kingdom. The dependent variable is the difference in employment shares of low and medium skilled jobs. Standard errors in parenthesis.

\subsection{Prediction 2: Wage Polarization}

Proposition 2 states that if a demand-side shock (computerization) has driven changes in the employment structure, we should observe a deeper wage growth at the extremes of the wage distribution than in the middle even in countries where the employment structure is not characterized by an increase in the employment share of low-skilled jobs.

To analyze this issue, we will compare changes in the wage structure in one 
country of continental Europe, i.e. Italy, with the US. Despite the fact that in Italy the share of employment in low-skilled jobs has not increased, the increase in the demand of manual tasks induced by computerization should lead to an increase in low-skilled wages in both countries.

Our source of data for Italian wages is the WHIP. ${ }^{18}$ It is a database of individual work histories, based on Italian social security institute (INPS) archives. The reference population is made up by all the people, Italian and foreign, who have worked in the Italian private sector even for only a part of their working career. A large representative sample has been extracted from this population: the sampling coefficient is about 1:180 for a dynamic population of 370,000 people. These data are collected through 20 surveys carried out yearly over the period 1985-2004.

Data on the US hourly wages (based on annual earnings divided by hours worked in the previous calendar year) come from the CPS March Samples (Autor et al. 2006).

Once collected, these data are used to observe the changing nature of inequality in different parts of the wage distribution. Figure 4 plots the annual average growth of real earnings by wage percentile. On the whole, in the last decades very low wages and very high wages have been the ones that have grown the most both in the US and in Italy. This evidence is very striking: despite the difference in the average wage growth in the two countries, the shapes of the curves are very similar. In particular, in both countries lowest wages have grown 1 log point more than median wages.

Wage polarization in Italy and in the US
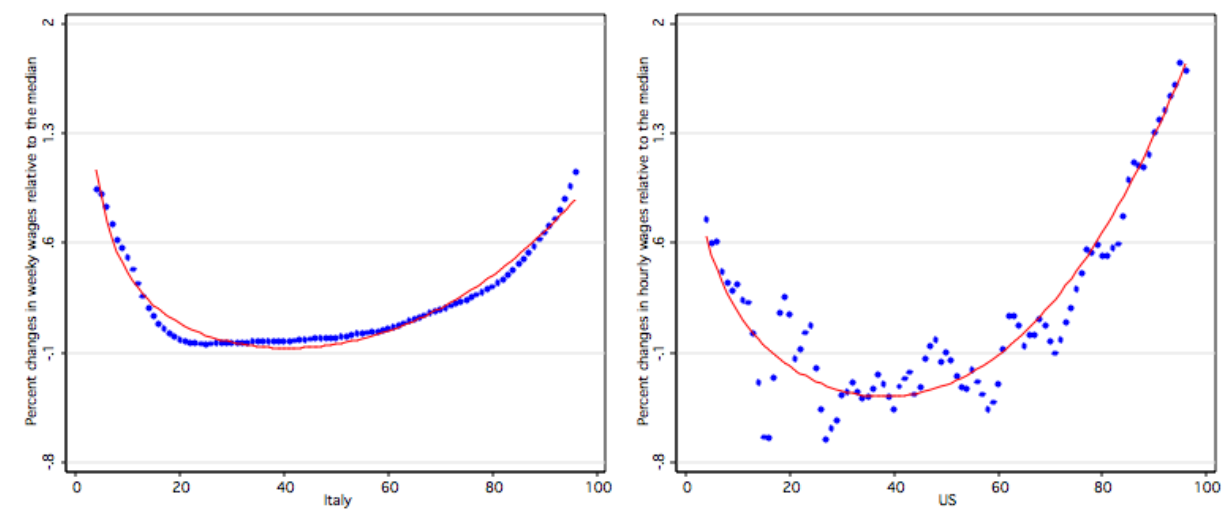

Figure 4: Annual average change in log wages by percentile of the wage distribution. Source: WHIP for Italy and CPS for the US (Autor et al. 2006).

To summarize, the empirical evidence for Italy shows a clear polarization pattern for wages and no convexification in the employment structure. In the US there has been the same pattern both in wages and in employment. Therefore, the Italian case is consistent with our theoretical predictions when $\phi=1$; the US case when

\footnotetext{
${ }^{18}$ The Work Histories Italian Panel, created by the center for employment studies Laboratorio R. Revelli. See http://www.laboratoriorevelli.it/whip.
} 
$\phi<1$. This evidence is in line with the different peculiarities of labour market institutions in the two countries and highlights the capability of the theoretical analysis to explain both the wage and the employment patterns of countries with heterogeneous institutional environments.

\subsection{Predictions 3: Involuntary Unemployment}

In our theoretical framework the effects of the computerization process on unemployment crucially depends on the attitude of labour market institutions. In this section we want to verify our third theoretical prediction: the lower is the difference in the employment shares of low- and medium-skilled jobs, the higher is the unemployment rate.

We exploit this correlation using data from the European labour force survey from 1993 to 2009. Figure 5 shows that the average unemployment rate and the difference in the proportion of low- and medium-skilled jobs are negatively correlated (the slope of the curve is different from zero at 1\%). Thus, countries with fewer job opportunities in low-qualified tasks have a higher share of unemployment over the labour force.

Furthermore, this result is confirmed by table 4, which presents the estimated results of an OLS regression for the effects of the difference in the employment shares of low- and medium-skilled jobs on the unemployment rate. Controlling for country fixed effects, we get a negative and statistically significant coefficient.

Difference in the proportion of low and medium-skilled jobs and unemployment

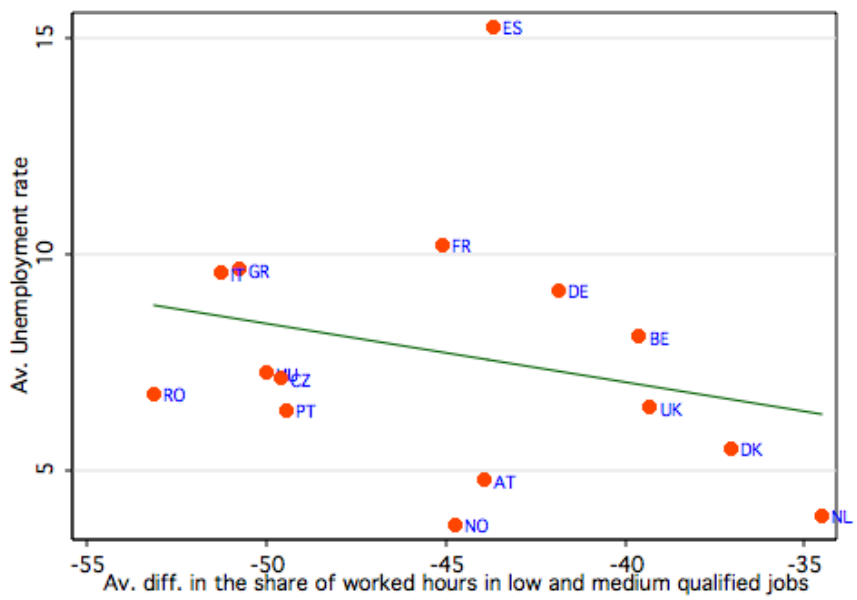

Figure 5: Source: Eurostat, 1993-2008. We use yearly data on every European country. We control for year and country fixed effects.

Summing up, the policy of labour market institutions is crucial in determining the effects of a demand-side shock on both the quality and quantity of job opportunities. 
Difference in the proportion of low and medium-skilled jobs and unemployment

\begin{tabular}{cc}
\hline Diff. empl. sh. & $-0.27^{* * *}$ \\
& $(0.03)$ \\
Country FE & YES \\
$R^{2}$ & 0.74 \\
Obs. & 225 \\
\hline
\end{tabular}

Table 4: Source: Eurostat, 1993-2009. The regression includes data on Austria, Belgium, Croatia, Germany, Denmark, Spain, France, Greece, Hungary, Italy, Holland, Norway, Portugal, Romania and United Kingdom. The dependent variable is the unemployment rate; the main explicative is the difference in employment shares of low and medium skilled jobs. Standard errors in parenthesis.

\section{Conclusions}

Autor et al. (2006) explain the US employment pattern with the sharp decrease of computing power price and the related diffusion of computers. Since technological diffusion and the following routinization process are global phenomena that have been affecting also European countries, we may expect that the European labor market has changed in a very similar way. However, wages and employment in many European countries are determined through a bargaining process between the confederations of trade unions and the association of entrepreneurs and, thus, they may not directly reflect changes in labor demand and supply as in a competitive labour market.

The comparison between employment patterns in the US and Europe shows a clear discrepancy: during the period 1988-2004, the US labor market was characterized by an employment increase both at the bottom and the top of the skills distribution; conversely, in many European countries the employment share of lowpaid jobs did not increase at all. Furthermore, we show that the lack of employment growth in low-skilled jobs is correlated with the emergence of unemployment and with the rigidity of the EPL.

In order to explain these patterns, we propose a theoretical framework that studies the effect of the technological diffusion in the labor market and that captures national peculiarities in the institutional environment. In particular, we give voice to the role played by unions in the process of wage setting. In our model, the technological change induces (i) a reduction of the employment share of routine labor tasks, typically replaced by computer capital; (ii) an increase in the employment share of abstract labor tasks that are complements to computers; and (iii) a shift in labour supply from medium- to low-skilled jobs whose effects on low-skilled manual employment strictly depend on the union employment target. When unions protect only their members (currently employed individuals), the effects of the increase in low-skilled supply will be weak. Thus, according to our theoretical analysis, unions can minimize the effects of the technological shock on the employment structure, which may also create involuntary unemployment.

The model is consistent both with our empirical findings and with the previous literature (i.e. Dustmann et al, 2007; Fortin, Lemieux, 1997 and Oesch and Rodriguez Menes, 2010). 


\section{References}

Andrews, M.; Nickell, S.J.; (1983), Unions, Real Wages and Employment in Britain 1951-79, Oxford Economic Paper, New Series, 35: 183-206.

Autor, D. (2010), The Polarization of Job Opportunities in the US Labor Market, Center for American Progress and the Hamilton Project, Washington.

Autor, D.; L. Katz; M.S. Kearney (2006), The Polarization of the U.S. Labor Market, The American Economic Review 96(2): 189-194.

Autor, D.; F. Levy; R. Murnane (2003), The Skill-Content of Recent Technological Change: an Empirical Investigation, Quarterly Journal of Economics 118(4): 1279-1333.

Blanchard, O.; L. Summers (1986), Hysteresis and the European Unemployment Problem, in (eds) NBER macroeconomics annual 1, MIT Press, Cambridge, MA.

Blau, F.D.; L. Kahn (1996), International Differences in Male Wage Inequality: Institutions versus Market Forces, Journal of Political Economy 104(4): 791-837.

Dustmann, C.; J. Ludsteck; U. Schanberg (2007), Revisiting the German Wage Structure, IZA Discussion Paper 2685.

Fortin, N.M.; T. Lemieux (1997), Institutional Changes and Rising Wage Inequality: Is There a Linkage?, The Journal of Economic Perspectives 11(2): 75-96.

Goos, M.; A. Manning; A. Salomons (2009), Job Polarization in Europe, The American Economic Review 99(2): 58-63.

Krugman, P. (1994), Past and Prospective Causes of High Unemployment, Federal Reserve Bank of Kansas City Economic Review 1994(1): 49-80.

Lemieux, T. (2007), The Changing Nature of Wage Inequality, Journal of Population Economics 21(1): 21-48.

Levy, F.; R. Murnane (2004), The New Division of Labor, Princeton University, New Jersey.

Levy, F.; P. Temin (2007), Inequality and Institutions in 20th Century America , NBER Working Papers No. 13106.

Nickell, S.J.; R. Layard (1999), Labor Market Institutions and Economic Performances, in Ashenfelter, O.; D. Card (eds) Handbook of Labor Economics 3C, Amsterdam, North Holland.

Oesch, D.; J. Rodriguez Menes (2010), Upgrading or Polarization? Occupational Change in Britain, Germany, Spain and Switzerland, 1990-2008 MPRA Pa- 
per, 21040.

OECD (1994), The OECD Jobs Study, Evidence and Explanations.

Olivieri, E. (2012), Il cambiamento delle opportunita' lavorative, in Checchi, D. (eds) Disuguaglianze diverse, Il Mulino, Bologna: 89-108.

Tijdens, K.; M. Van Klaveren (2007), Collective Bargaining and Coverage, WIBAR Report No. 5

Wright, E.O.; R. Dwyer (2003), The patterns of job expansions in the USA: a comparison of the 1960s and 1990s, Socio Economic Review, 1(3): 289-325. 


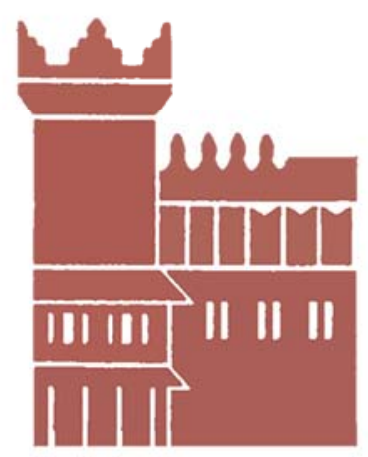

Alma Mater Studiorum - Università di Bologna DEPARTMENT OF ECONOMICS

Strada Maggiore 45

40125 Bologna - Italy

Tel. +39051 2092604

Fax +390512092664

http://www.dse.unibo.it 